\title{
Specimen Size Effect on Bend Properties of Molybdenum Doped with Potassium-Silicate
}

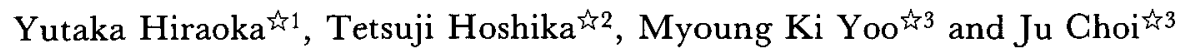

it Dept. Appl. Phys., Fac. Sci., Okayama Univ. of Science, 1-1 Ridai-cho, Okayama 700. t2 Graduate School,

Okayama Univ. of Science, 1-1 Ridai-cho, Okayama 700. \$3 Korean Inst. of Science \& Technology, P.O. Box 131, Cheongryang, Seoul / Korea.

Received November 28, 1994

\section{SYNOPSIS}

In order to investigate the effect of specimen size on the strength and the ductility of molybdenum, bend angles at temperatures between liquid nitrogen temperature and room temperature were carried out for the recrystallized sheet of molybdenum doped with pottasiumsilicate. In this study the low-temperature fracture strength and ductility of the material were represented by critical stress and critical temperature, respectively.

The results are summarized as follows.

(1) As the specimen width decreased from $4 \mathrm{~mm}$ to $1 \mathrm{~mm}$ with the specimen thickness being $1 \mathrm{~mm}$, the critical stress tended to increase whilst the yield strength was almost unchanged.

(2) Increase of the critical stress with decreasing the specimen width was related with the crack generation and propagation characteristics. The size of the crack generation site tended to be smaller, as the specimen width decreased.

(3) The critical temperature tended to decrease as the specimen width decreased. This result was attributed mainly to the increase of the critical stress.

KEY WORDS

doped molybdenum, specimen width, critical stress, critical temperature, fractography

\section{Introduction}

Recently we investigated ${ }^{1)}$ the effect of specimen size on the ductile-brittle transition characteristics in the recrystallized sheet of pure molybdenum. The bend-test specimen with thickness of $0.3 \mathrm{~mm}$ indicated a lower yield strength and a better low-temperature ductility than the specimen with thickness of $0.5-1.0 \mathrm{~mm}$. However the effect of specimen width ranging $1-4 \mathrm{~mm}$ with the thickness being $1.0 \mathrm{~mm}$ on the strengths and ductility were not recognized.

The purpose of this study was to measure the bend properties of the pottasium-silicate doped molybdenum sheet and investigate the effect of specimen thickness on the strengths and ductility. It is well known that the doped molybdenum has a good ductility at low temperatures ${ }^{2-4)}$ and a superior strength at high temperatures, ${ }^{5,6}$ even after the complete recrystallization. However there is no any report on the bend fracture behavior of the small-size specimen of this material.

\section{Experimental}

The starting material was a pottasiumsilicate doped molybdenum sheet of about $1 \mathrm{~mm}$ thickness which had been supplied by Toho Kinzoku Co., Ltd. From this sheet rectangular specimens with length of $25 \mathrm{~mm}$ and width ranging $1-4 \mathrm{~mm}$ were cut out and were subjected to the heat treatment at $2073 \mathrm{~K}$ for $3.6 \mathrm{ks}$ in a vacuum of $1.3 \times 10^{-4} \mathrm{~Pa}$. The microstructure after the heat treatment was a very large and elongated grain structure including a number of relatively small and equiaxed grains in the matrix and at the grain boundaries.

Three-point bend tests were carried out at temperatures between liquid nitrogen temperature and room temperature at a crosshead speed of $0.017 \mathrm{~mm} \mathrm{~s}^{-1}$. From the load-displacement curve, strength $(\sigma / \mathrm{MPa})$ and 
bend angle ( $\alpha$ /degree) were calculated by using the following equations.

$$
\begin{gathered}
\sigma=3 a P / w t^{2} \quad-(1) \\
\alpha=2\left\{90-\left[\cos ^{-1}\left(a /\left(a^{2}+(2 r+t-d)^{2}\right)^{1 / 2}\right)\right]+\right. \\
\left.\left.\left[\cos ^{-1}(2 r+t) /\left(a^{2}+(2 r+t-d)^{2}\right)^{1 / 2}\right)\right]\right\} \\
-(2)
\end{gathered}
$$

where $P$ is the applied load(N), $w$ and $t$ are the specimen width(mm) and thickness(mm), respectively, $2 a$ is the span of the supporting pins(mm), $2 r$ is the diameter of the loading $\operatorname{pin}(\mathrm{mm})$ and $d$ is the displacement of the crosshead(mm). In this study the specimen that withstood over a displacement of $7 \mathrm{~mm}$ was defined as the "full-bend" one for convenience' sake.

The fracture surfaces of the specimens failed at liquid nitrogen temperature and/or at about $153 \mathrm{~K}$ were examined by using a scanning electron microscope. The crack generation and propagation characteristics were investigated, and the size of the crack generation site was measured.

\section{Results}

The effect of specimen width on the yield and the maximum strengths is shown in Fig.1 and Fig.2, respectively. There was no size dependency in the yield strength at a given temperature. On the other hand, the maximum strength at higher temperatures (e.g. 223, 290K) also demonstrated almost no size dependency. However the maximum strength at lower temperatures (e.g. $77,153,173 \mathrm{~K}$ ) tended to

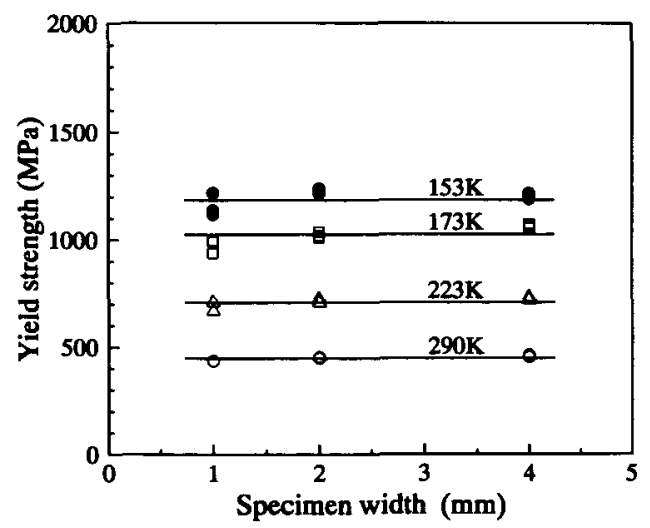

Fig.1 Effect of specimen width on yield strength.

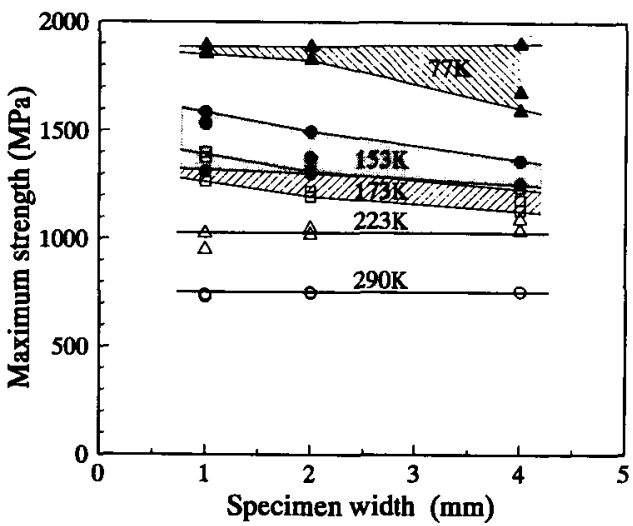

Fig.2 Effect of specimen width on maximum strength.

increase as the specimen width decreased, though there was a scatter in the data. It is noted the maximum strength at lower temperatures corresponds to the fracture strength. The effect of specimen width on the bend angle is shown in Fig.3. The ductility at lower temperatures tended to increased as the specimen width decreased, though there was a scatter in the data. These results were not consistent with the results for the pure molybdenum ${ }^{1)}$. In pure molybdenum both the strength and the ductility were almost unchanged irrespective of specimen width ranging $1-4 \mathrm{~mm}$ with the thickness being $1.0 \mathrm{~mm}$.

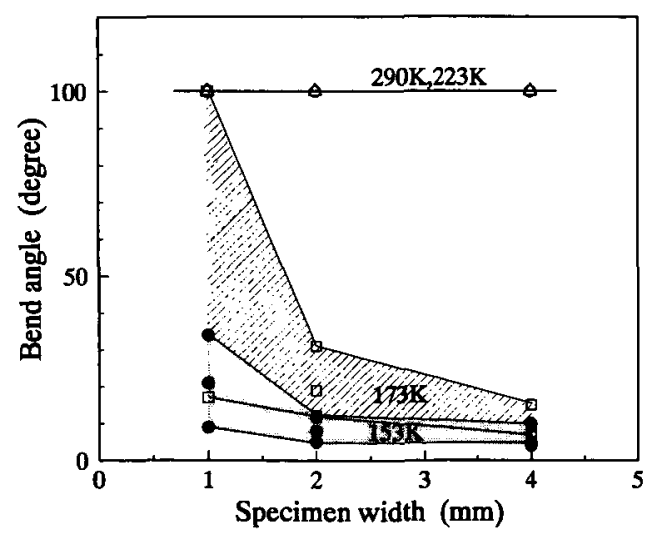

Fig.3 Effect of specimen width on bend angle.

In this study the low-temperature fracture strength and ductility of the material were represented by critical stress and critical temperature, respectively. These two 
parameters can be determined by using the temperature dependencies of the yield and the maximum strengths for each material in a manner as mentioned in the previous paper ${ }^{1)}$. The definition of the critical stress and the critical temperature is schematically shown in Fig.4. The critical stress is the stress that

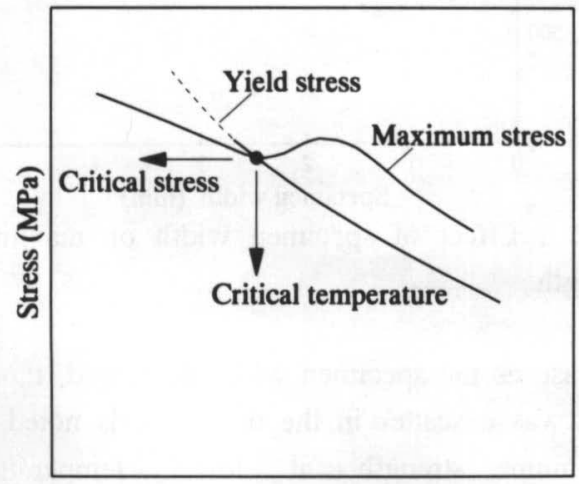

Test temperature (K)

Fig.4 Definition of critical stress and critical temperature.

propagates microcrack(s) intergranularly and/or transgranularly at and around the critical temperature. The critical temperature is an expression of the ductile-to-brittle transition temperature (DBTT). The material having a lower DBTT generally demonstrates a higher ductility at lower temperatures and hence the reciprocal of DBTT is a measure of the lowtemperature ductility ${ }^{7}$. The critical stress and the critical temperature are plotted against the specimen width in Fig.5 and Fig.6, respectively. The critical stress increased and, in contrast, the critical temperature decreased as the specimen width decreased. The highest value in the critical stress and the lowest value in the critical temperature at a given specimen width were derived from the highest values of maximum strength at lower temperatures. In contrast the lowest value in the critical stress and hence the highest critical temperature were derived from the lowest values of maximum strength. These results are again not consistent with those obtained for the pure molybdenum ${ }^{1)}$. In the latter material both the critical stress and the critical temperature were almost no dependency of the specimen width ranging $1-4 \mathrm{~mm}$.

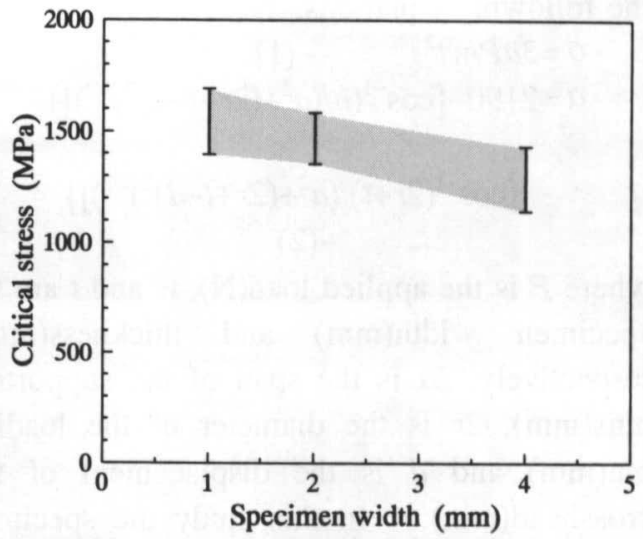

Fig.5 Plots of critical stress against specimen width.

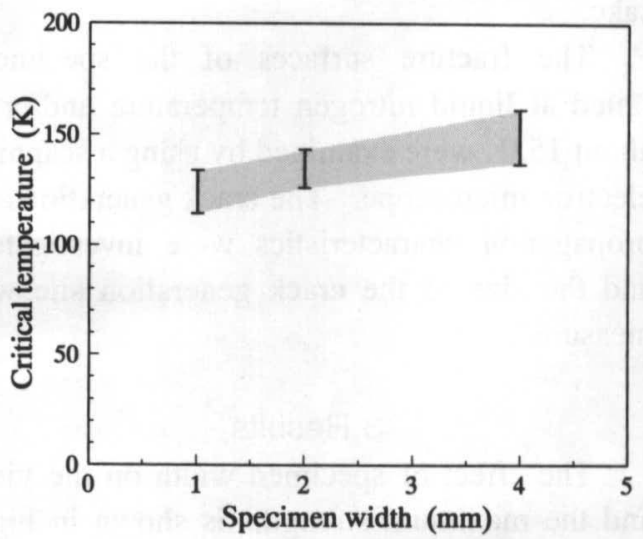

Fig.6 Plots of critical temperature against specimen width.

Typical fractographs of the specimen failed at liquid nitrogen temperature is shown in Fig.7. The crack generated at one of the equiaxed

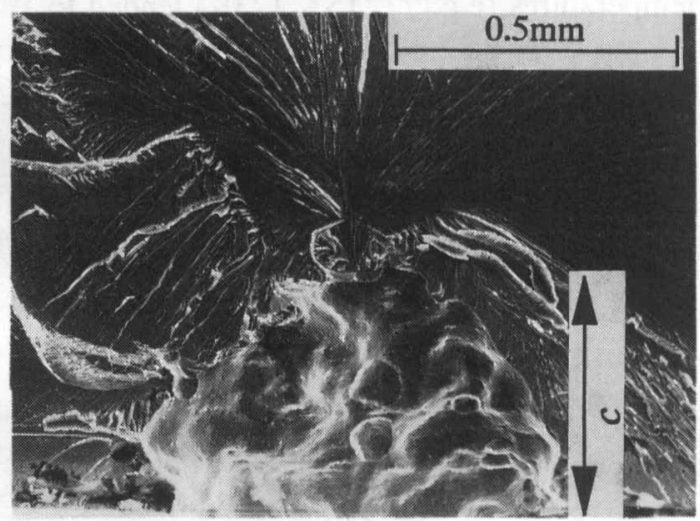

Fig.7 Typical fractograph of doped molybdenum failed at liquid nitrogen temperature. 
grains and then propagated mostly transgranularly. Here the size of the crack generation site was defined as the size of the grain(s) as indicated in the figure. Such fractography is quite similar to that in our previous study ${ }^{4)}$.

\section{Discussion}

In our previous study ${ }^{4}$ it was demonstrated that the doped molybdenum and the singlecrystalline molybdenum prepared by means of secondary recrystallization ${ }^{8)}$ have some similarities in the fracture behavior, that is "crack propagation controlling". First relatively weak boundaries exist and thereby the crack always generates at one(s) of these boundaries. Secondly the crack then propagates along specific crystal planes in the single crystal ${ }^{9,10)}$ or mostly transgranularly in the doped molybdenum ${ }^{4)}$. Lastly the fracture strength depends on the size of the crack generation site which is identified to be the island grain(s) in the single crystal and the equiaxed grain(s) in the doped molybdenum. By using SEM the size of the site (c) was measured for each specimen failed at liquid nitrogen temperature and at about $153 \mathrm{~K}$. The maximum strength is plotted against $c$ in Fig.8. The relationship between the fracture strength at liquid nitrogen temperature and the size of island grain obtained for the single crystals having axial orientation near $\langle 011\rangle^{8,10,11)}$ is also shown by the thin solid line in the figure.

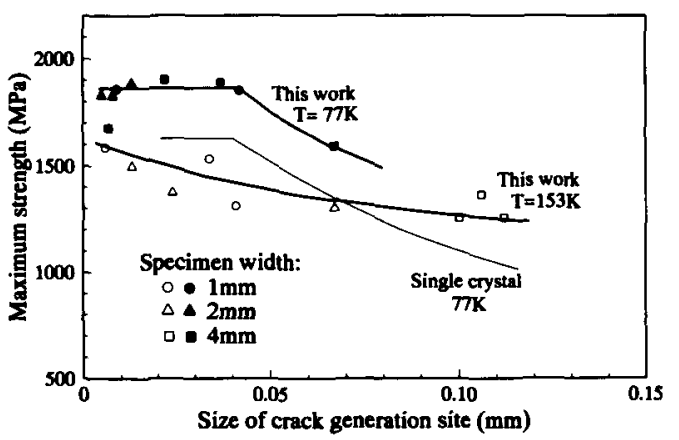

Fig.8 Plots of maximum strength at liquid nitrogen temperature and $153 \mathrm{~K}$ against size of crack generation site.
Judging from the figure, first, the maximum strength of the doped molybdenum tended to decrease as the size of the crack generation site increased, qualitatively in a similar manner as the single-crystalline molybdenum. However it is noted that there were only limited numbers of applicable data and there was a scatter in the data. Secondly the size of the crack generation site tended to increase generally as the specimen width increased. Such tendencies were more distinct in the maximum strength at $153 \mathrm{~K}$ which is nearer to the critical temperature. Thereby the experimental result that the maximum strength at lower temperatures or the critical stress increased as the specimen width decreased is interpreted as follows. As the specimen width decreases, the area of the specimen contacting with the loading pin may be decreased. This result means that the numbers of the weak equiaxed grains and possibly the numbers of the grains having larger size within this area are also decreased. In these ways it should be insisted that the increase of the critical stress with decreasing the specimen width is not intrinsic but extrinsic.

Furthermore the scatter in the maximum strength at lower temperatures or in the critical stress was attributed to the difference in the size of crack generation site. On the other hand the decrease of the critical temperature as the specimen width decreased is interpreted as follows. The critical temperature originally depends not only on the critical stress but on the yield strength. However the yield strength demonstrated almost no dependency of the specimen width ranging $1-4 \mathrm{~mm}$. Consequently the critical temperature was only a function of critical stress and the critical temperature decreased corresponding to the increase of the critical stress.

\section{Conclusions}

(1) The maximum strength at lower temperatures and the critical stress tended to increase as the specimen width decreased from $4 \mathrm{~mm}$ to $1 \mathrm{~mm}$. On the other hand the yield strength at a given temperature demonstrated 
almost no dependency of the specimen width. The increase of the critical stress was attributed to the general decrease of the size of crack generation site as the specimen width decreased. (2) The bend angle at lower temperatures increased and the critical temperature decreased as the specimen width decreased. This result was attributed mainly to the increase of the critical stress.

\section{References}

1) Y.Hiraoka and T.Hoshika: J. Jpn. Soc. Powder \& Powder Met., 42(1995)108.

2) R.Eck: Planseeber. Pulvermet., 3(1974)165.

3) E.Kalns: Climax report L-303-09, (1976).

4) Y.Hiraoka and M.Okada: Z. Metallkde., 79 (1988)519.

5) K.Takebe, T.Akiyama, K.Shimatani and M.Endoh: Refractory Met. \& Hard Mater., (4) (1985)182.
6) Y.Fukasawa, T.Matsumoto, S.Ogura and H.Koizumi: Proc. 11th Plansee Sem., (eds) H.Bildstein \& H.M.Ortner, Metallwerk Plansee GmbH, Reutte/Austria, (1985), p.292.

7) Y.Hiraoka, S.Yoshimura and K.Takebe: Int. J. Refractory Met. \& Hard Mater., 12(19931994)261.

8) Y.Hiraoka, M.Okada, T.Fujii and R.Watanabe: J. Less-Common Met., 97 (1984)99.

9) Y.Hiraoka, M.Okada, T.Fujii and R.Watanabe: J. Less-Common Met., 97 (1984)117.

10) Y.Hiraoka, T.Fujii, M.Okada and R.Watanabe: Trans. Jpn. Inst. Met., 26 (1985)814.

11) T.Fujii, R.Watanabe, Y.Hiraoka and M.Okada: Trans. Nat. Res. Inst. Met., 28 (1986)1. 